\title{
THE IMPACT OF INCORPORATING STYLISTIC MODELS OF INVERSION IN TEACHING GRAMMAR ON STUDENTS' COMPREHENSION OF LITERARY TEXT
}

\author{
Hasan Mohammed Saleh JAASHAN \\ King Khalid University, Saudi Arabia \& Sanaa University, Yemen \\ hmsaleeh@kku.edu.sa
}

Manuscript received 27 July 2020

Manuscript accepted 17 September 2020

*Corresponding author

https://doi.org/10.33736/ils.2447.2020

\begin{abstract}
Pedagogical stylistics increases EFL learners' awareness about the way the language functions in different texts. It also enhances innovative learning and teaching. This study aims at knowing the impact of incorporating stylistic models of inversion in teaching grammar on students' comprehension of literary texts. It also aims to explore the learners' perceptions about incorporating them in grammar courses. The models were adopted by (Galperin, 1977). A total of 85 EFL learners at King Khalid University participated in this study; 41 are students of Grammar III and are divided into two groups $(15,26) ; 44$ are students of Grammar IV and are divided into two groups $(20,24)$. The second phase of the research is a unified long text exam that contains stylistic models of inversion in literary texts and is given to all students. Generally, the post-test results show that the participants identify stylistic models of inversion that help them understand the meaning of texts. Moreover, the quantitative approach shows the learners' preference for incorporating models in grammar courses because they are important in comprehending literary texts. The study recommends considering stylistic implications in teaching grammar in general and stylistic models of inversion in particular.
\end{abstract}

Keywords: Pedagogical stylistics; models of inversion; teaching grammar; literary texts; stylistic principles

\section{Introduction}

Stylistics commonly can be described as the study of the oral or written style of language usage in different linguistic or situational contexts. It is related to discourse analysis. From the beginning of the development of stylistics as a field of applied

The Impact of Incorporating Stylistic Models of Inversion in Teaching Grammar on Students' Comprehension of Literary Text 
linguistics, the major concerns of stylistic investigations were with literary texts. So, it was sometimes called literary linguistics, or literary stylistics (Crystal, 1997). Nowadays, the perspective about stylistics has becomes wider. It studies the linguistic features of different types of texts beyond literature; such as advertisements, manuals recipes, media discourse such as films, news reports, political speeches, proclaiming that all texts are important and deserved to be analysed and they have been within the interest of stylisticians.

Because of such an important growth in stylistics, some European countries adopt pedagogical stylistics as an essential component of educational system. It also increases the learners' perception of different features of the language and the ways in which they function in various types of text with miscellaneous effects (Carter \& Nash, 1990; Kang, 2018; Nørgaard, Montoro, \& Busse, 2010; Widdowson, 1975). In the UK, the teachers and academicians share common idea about the importance of stylistics in first language (L1) English teaching. As a result, stylisticians organised many joint workshops with teachers to create solid beliefs about the interrelated relation between stylistics and grammar (Borg \& Burns, 2008; Nespor, 1987; Watson, 2015). They explained the different stylistic principles to the teachers and ask them to apply these in teaching. Teachers then asked their students to use the stylistic features they have learned to analyse the language of literary texts by examining an author's choices of different linguistic features and considering the kinds of effects the texts have on them. The students show outstanding performance in literary text analysis (Cushing, 2018). Therefore, when teaching literature or language acquisition for English as Foreign Language (EFL) learners, stylistic implications should be considered because they improve students' academic performance, specifically, in writing creativity and in texts understanding (Fogal, 2015; Giovanelli \& Clayton, 2016; Simpson, 1999). This creativity in teaching boosts the learner- centered styles (Ghanizadeh \& Jahedizadeh, 2016). Consequently, this study focuses on one particular issue of stylistic implications; that is stylistic inversion which has the following main specific purposes:

1. To study the impact of incorporating stylistic models of inversion in teaching grammar on students' comprehension of literary texts.

2. To explore the learners' perception of incorporating stylistic models of inversion in grammar courses.

\section{Hypothesis}

The study hypothesises that there is a statistically more significant effect of learning stylistic models of inversion in texts than in sentences on student's comprehension of literary text. Bakhtin (2004) in his research taught students parataxis sentences, which he then tested them to examine their creativity in writing. He concludes that teaching parataxis without considering stylistic elucidation lacks students' creativity significance and it does not help them to improve productive skills creativity. Therefore, stylistic elucidation is very significant to comprehend text. Huang (2019) in his study, discusses the applications of stylistics in college English teaching reading. He concludes that implying the theory of stylistic analysis into college

The Impact of Incorporating Stylistic Models of Inversion in Teaching Grammar on Students' Comprehension of Literary Text 
English reading class can improve students' understanding of articles from words to texts and develop their comprehensibility.

\section{Theoretical framework}

\section{Stylistics and teaching grammar}

The English language has a large number of grammatical rules which EFL learners should learn because they improve their basic literacy skills and equip them with techniques of mastering Standard English language skills. However, there are different linguistic registers or genres that require breaking the grammatical rules and deviating from the linguistic norms. They are called foregrounding possibilities which are as large as grammatical rules (Short, 1996). These linguistic metaconcepts, from my point of view, are mandatory for EFL learners because they show them how to understand and analyse different literary texts which are full of foregrounding features. Van and Peter (2020) manifest the importance of making connection between concepts from traditional grammar and underlying metaconcepts from linguistic theory in order to boost in-depth understanding of grammar. Therefore, incorporating stylistic features in grammar courses increases the students' awareness of grammatical structures through actualising this knowledge in their writing in one hand and being able to analyse the writings of others on the other hand (Giovanelli, 2010). It also bridges the gap between the grammar rules in textbooks and authentic speech (Cancellaro, 2015). Myhill, Jones, Lines, and Watson (2012), made use of rhetorical grammar and principles from stylistics, and they concluded that using contextualised grammar in teaching could have positive results on students' interpretation of a text, on their writing ability, and meta-linguistics. Therefore, stylistics is a hands-on method that makes learners able to interpret and explore the conceptual meaning of texts (Jeffries \& Mclntyre, 2010; Simpson, 2014). Cushing (2018) studied the reader-response theory as a method of thinking about teaching grammar and poetry in the English classroom, and he reached concluded that the reader-response theory approach, to a great extent, offers an essential contextualised approach for discovering how language and grammar work. Whiteley and Canning (2017) argue that stylistics and readerresponse theory in this concern are integral parts because the reader himself decides the relationship between textual form and interpretative effects of a text.

The Department for English (DfE, 2013) recommends that incorporating stylistics in teaching English grammar exposes students to able to know how the different linguistic features such as figures of speech, vocabulary choice, grammar, and text structure increases the understanding of meaning. They also study the effectiveness of grammatical features of the text they read. Consequently, students draw on these linguistic features or stylistic principles they have learned and use them in their productive skills (writing and speaking) to achieve a particular effect. Similarly, they recognise the different possible responses to a text and make a unique personal response as a result of evaluating and analysing it. In a nutshell, Cushing (2018) suggests that learners should learn grammar in authentic texts and they should be given a chance to interpret a text.

The Impact of Incorporating Stylistic Models of Inversion in Teaching Grammar on Students' Comprehension of Literary Text 
Besides those scholars who encourage incorporating stylistic principles in English school curriculum (L1), there are other scholars (Sotirova, 2016) who discussed the pedagogical stylistics' aims and processes in a university context, and others (Burke, Csabi, Week, \& Zerkowitz, 2012; Fogal, 2015) who discussed it in the Second Language (L2) context. On this basis, pedagogical stylistics becomes an interest to many scholars worldwide because it aims to sensitise students to language use within the actual texts (Clark \& Zyngier, 2003; Hall, 2014). Therefore, incorporating stylistic models of inversion in grammar courses is important because it is a real practice of pedagogical stylistics.

\section{English word order}

All languages worldwide have $\mathrm{S}, \mathrm{O}, \mathrm{V}$ as labels for word order categorisations. Each language adopts one of the six ordering patterns of SOV as its basic word order. A study done by Tomil (1986) proposed that the pattern SOV is a basic word order of $45 \%$ of the world's languages and SVO is the pattern word order of $42 \%$ of the world's languages and only 9\% of languages have VSO pattern (Dryer, 2005; Song, 2012). The English language is one of the languages that adopt SVO pattern. It has fixed word orders that make the subject comes at the beginning of a transitive sentence followed by a verb then by an object (SVO). That system shows the relationship between the parts of a sentence and makes most of the English sentences come under this model and conform to this order. Jesperson (1943) said "... the English language has developed a tolerably fixed word order which in the great majority of cases shows, without fail, what is the subject of the sentence" ( $p$. 99). Adjectives modify nouns, pronouns. They come directly before the noun they modify. Adverbs modify verbs, adjectives, other adverbs, or entire sentences. They occur initially, medially, or finally in a sentence. However, there are inversions that are commonly used, and are parts of English grammatical structure. They are called grammatical inversions. They only change the structural meaning of a sentence. In interrogative statements, verbs, helping/linking verbs, and auxiliaries always come before the subjects, for instance;

Was that book heavy? (link.v $+S+$ adj)

Where did he go? (hel. $v+S+V)$

Can you help me? (mod. $v+S+V+O)$.

Also in exclamations, adjectives come before the linking verbs and the subject, for example;

What a beautiful picture it is! (Adj+S+ link.verb).

These are grammatical inversions in which the structural meaning of a sentence is changed. Therefore, grammar courses, in general, contain all these rules, and the EFL learners worldwide are familiar with them.

\section{Stylistic inversion}

Apart from the above-mentioned common grammatical inversions, there is another type of inversion which is called stylistic inversion/locative inversion. It commonly exists in literary texts. Crystal (2011) defines it as "a term used in

The Impact of Incorporating Stylistic Models of Inversion in Teaching Grammar on Students' Comprehension of Literary Text 
grammatical analysis to refer to the process of or result of syntactic change in which a specific sequence of constituents is seen as the reverse of another" (p. 64). The main aim of stylistic inversion is to attach stress or to add emotional colouring to the surface meaning of the utterance. Stylistic inversion does not change the structural meaning of a sentence as the grammatical inversion does (Bailyn, 2004; Culicover \& Levine, 2001). The change in the juxtaposition of sentence words (stylistic inversion) adds some super-structural function to the sentence; like adding emotional colouring (stress) to the surface meaning of a sentence. Therefore, intonation is always linked with stylistic inversion. Generally, the inverted constituents of a sentence get full volume of stress than they would be in ordinary (uninverted) utterance. Galperin (1977) mentions different models of stylistic inversion. Out of them the researcher selects the following common and repeated ones, which would be the concern of this study.

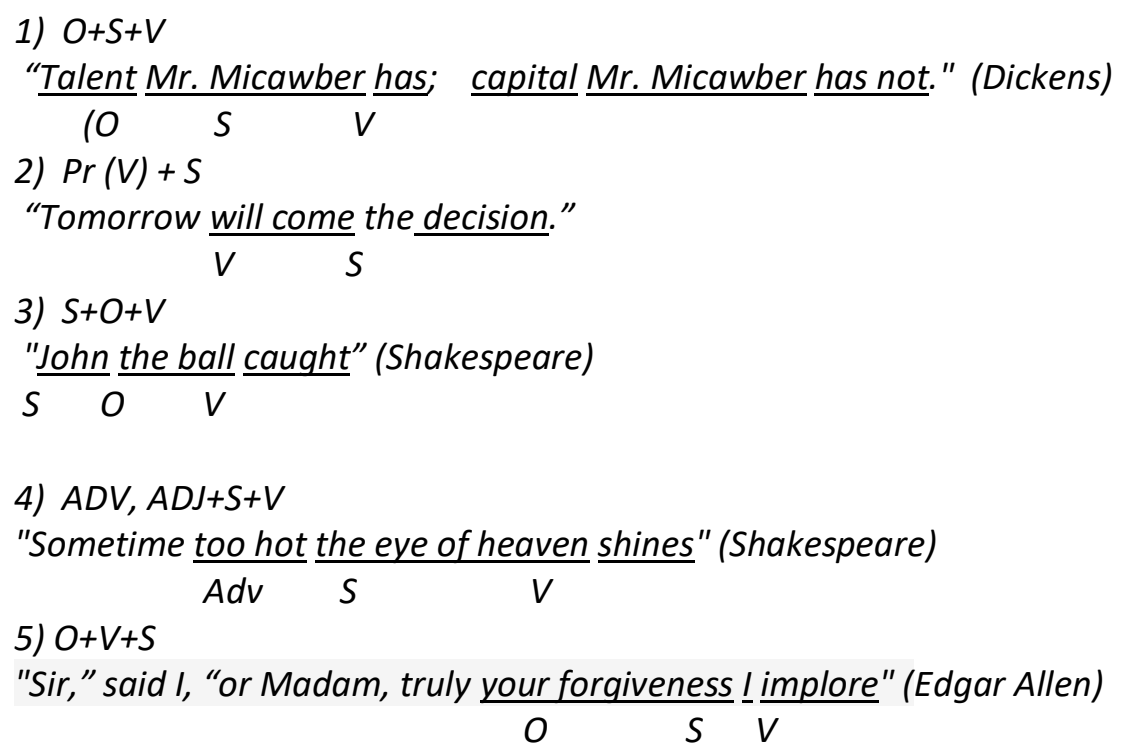

The literary writers, as part of literary necessity, make their writing more aesthetic by deliberately deviating from the common language rules (as literary necessity) in order to make the piece of literature perceptually prominent (Short, 1984). The Arab linguist Abu Al-Sarraj (316 H) defines the literary necessity or deviation as a deliberate deletion, addition, inversion, substitution in a literary works especially in poetry in order to enhance meaning or maintain metre and rhyming scheme in the lines (Anees, 2016). Literary license or creative license gives literary writers room for manipulation and use different linguistic variants such as deviating from the common linguistic rules or ignoring some parts of grammar for the sake of artistic purposes. So literary writers use stylistic devices such as focusing on a particular point or changing the readers attention from a particular point to another to achieve stylistic effect and create aestheticism.

Literature and literariness are terms related to language of literary works but they are different in one major aspect that makes them controversial. In 1921 Roman Jakcobson differentiated between these two terms by saying that the subject

The Impact of Incorporating Stylistic Models of Inversion in Teaching Grammar on Students' Comprehension of Literary Text 
of literary science is literariness, that is, that which makes a given work a literary work. Literariness is the way that distinguishes literary texts from non-literary texts. Therefore, literariness shifts the focus of the reader to the language itself, often with an estranging or de-familiarising effect, but literature is using language in a peculiar way (Baldick, 1996).

\section{Methodology}

The researcher incorporated the stylistic models of inversion items in grammar courses (III and IV). Learners of one section from Grammar III and the learners of one section of Grammar IV had been taught the inversion models in only sentences. The learners of the other two sections had been taught the inversion models in literary texts. Then the researcher examined all learners by giving them literary text test that contained inversion models. The purpose of this text was to examine, generally, the performances of participants in identifying the inversion models and to know which method was effective in teaching models, whether it is the sentencebased or the text-based. An online questionnaire was also used to know the learners' perception about incorporating stylistic models of inversion in grammar courses.

\section{Practical study}

Stylistic inversion as one of the figures of speech at the syntactic level are found in literary texts. Unless students are aware of these devices, their understanding of literary text is potentially skeptically. Most of the students think that literary works that contain stylistic inversion are merely reflections of the writers' moods and they are baseless in language rules. However, such perception has vanished after EFL learners become familiar with it and knew the systematic way of using stylistic models in literature. This study was conducted on the students of Grammar III and IV, Faculty of Languages and Translation at King Khalid University. Two sections were in grammar III with 15 and 26 students and two others are in grammar IV with 20 and 24 students respectively. The researcher allocated two lectures for every section explaining the definition of stylistic inversion and its different models as they appear in literary texts. The students in one section of Grammar III were taught the models of inversion in just sentences and the students in the other section were taught inversion's models in texts. A similar technique was done with the students of grammar IV. The students of the first section were taught stylistic inversion's models in mere sentences and the students in the other section were taught the stylistic models of inversion in contexts.

The study aimed to find out the effective methodology that should be followed to teach stylistic models of inversion in grammar courses, whether it is sentencebased methodology or the text- based. On one hand, the students of one section from Grammar III and the students of one section from Grammar IV were taught inversion models in only sentences. On the other hand, the students of one section form grammar III and the students of one section from grammar VI were taught inversion models in texts in order to compare the participants' performance in both

The Impact of Incorporating Stylistic Models of Inversion in Teaching Grammar on Students' Comprehension of Literary Text 
sections (those who are taught inversion models in sentences and those who were taught them in context) to decide which teaching modality is effective. The way to judge so was a unified test given to all sections. The test contained eight long literary texts with stylistic models of inversion inside. The test rubric asked students to carefully read the texts, underline the inversion models, and re-write them in the proper grammatical word order (uninverted utterances) (see the test copy). The students in general showed progress in comprehending literary texts that contain inversion models. They underlined the different inversion models, and reverted them to the normal word orders that ease understanding the meaning the author wants to convey. SPSS program was used to analyse the results which run as follows:

1. Grammar III (compare between the performance of the students in group 1 who are taught stylistic models of inversion in only sentences and the students in group 2 who are taught stylistic models of inversion in texts).

2. Grammar IV (compare between the performance of the students in group 1 who are taught stylistic models of inversion in only sentences and the students in group 2 who are taught these stylistic models of inversion in texts).

3. Grammar III, IV (compare between the performances of participants according to the level).

The post-test results show the following:

RQ1: The impact of incorporating stylistic models of inversion in teaching grammar on students' comprehension of literary texts.

\section{Grammar III}

Table 1

Group statistics for Grammar III

\begin{tabular}{llllll}
\hline Teaching & & $\mathrm{N}$ & Mean & Std. Deviation & $\begin{array}{l}\text { Std. Error } \\
\text { Mean }\end{array}$ \\
\hline Overall & Sentence & 15 & 1.4000 & .37261 & .09621 \\
& Text & 26 & 1.5048 & .46027 & .09027 \\
\hline P. Value & .458 & & & & \\
\hline
\end{tabular}

Table 1 shows the result for both groups in Grammar III. Generally students in both sections performed well in analysing and understanding the literary texts that contain stylistic models of inversion. The text-based group had slightly higher scores $(M=1.50)$ in comparison to its sentence-based counterpart $(M=1.40)$. There were no statistically significant differences between the groups attributed to the explicit instruction of grammar III ( $p$ value $=.458$ ). In a nutshell, both methodologies (text or sentence) are effective in teaching stylistic models of inversion.

The Impact of Incorporating Stylistic Models of Inversion in Teaching Grammar on Students' Comprehension of Literary Text 


\section{Grammar IV}

Table 2

Group Statistics for Grammar IV

\begin{tabular}{llllll}
\hline Teaching & & N & Mean & Std. Deviation & $\begin{array}{l}\text { Std. Error } \\
\text { Mean }\end{array}$ \\
\hline Overall & Sentence & 20 & 1.4438 & .44329 & .09912 \\
& Text & 24 & 1.6146 & .40365 & .08239 \\
\hline P. Value & .193 & & & & \\
\hline
\end{tabular}

Table 2 shows the result for both groups in Grammar VI. Similar to Grammar III, students in both sections perform well in analysing and understanding the literary texts that contain different stylistics models of inversion. The text based group scored slightly better $(M=1.61)$ in comparison to its sentence based counterpart $(M=1.44)$. There were no statistically significant differences between the groups attributed to the explicit instruction of grammar IV ( $p$ value $=.193$ ). It is concluded that, both methodologies are effective in teaching inversion models.

\section{According to Level}

Table 3

Group statistics according to level

\begin{tabular}{llllll}
\hline Level & & $\mathrm{N}$ & Mean & $\begin{array}{l}\text { Std. } \\
\text { Deviation }\end{array}$ & $\begin{array}{l}\text { Std. Error } \\
\text { Mean }\end{array}$ \\
\hline Overall & Grammar 3 & 41 & 1.4939 & .44278 & .06915 \\
& Grammar 4 & 44 & 1.5369 & .42589 & .06421 \\
\hline P.value & .649 & & & & \\
\hline
\end{tabular}

Table 3 compares the performance of levels III and VI. The students in both levels generally did well in analysing literary texts that contain stylistic models of inversion. There were no statistically significant differences between students in the two levels of study ( $p$ value, .649). The very small difference in performance between Level III $(M=1.53)$ and Level VI $(M=1.49)$ has no statistical significance. That means stylistic models of inversion can be taught in either levels.

RQ2: The learners' perception towards incorporating stylistic models inversion in grammar courses after they learned them.

Table 4

Descriptive Statistics

\begin{tabular}{llllllc}
\hline Statement & \multicolumn{3}{c}{ N MinimumMaximum Mean } & $\begin{array}{c}\text { Std. } \\
\text { Deviation }\end{array}$ \\
\hline $\begin{array}{l}\text { 1. I think inversion models are not important to } \\
\text { be included in grammar. }\end{array}$ & 47 & 2.00 & 5.00 & 4.2766 & .79951
\end{tabular}

The Impact of Incorporating Stylistic Models of Inversion in Teaching Grammar on Students' Comprehension of Literary Text 
2. Literary texts are difficult to understand $\begin{array}{lllll}47 & 1.00 & 5.00 & 4.2766 & 1.05711\end{array}$ because they are different from Standard English we learn.

3. It is important to know the features of $\begin{array}{lllll}47 & 2.00 & 5.00 & 4.2128 & .88308\end{array}$ language and the ways in which they function in various types of text.

4. I think models of inversion are important. $47 \quad 1.00$ $\begin{array}{lll}5.00 & 4.1277 \quad 99164\end{array}$

5. I prefer incorporating models of inversion in $47 \quad 2.00$ $\begin{array}{lll}5.00 & 3.9787 & .82064\end{array}$ teaching grammar.

6. Inversion models help me comprehend literary $47 \quad 2.00$ texts.

7. After understanding inversion, I find myself able to write some literary texts.

8. Inversion lets me connect between

$47 \quad 1.00$ grammatical rules and literary texts.

9. Inversion helps me understand how writers use $47 \quad 1.00$ language features.

10. Inversion enhances learners' autonomous $47 \quad 1.00$ analysis of literary texts.

11. I can understand literary texts easily without $\begin{array}{llllll}47 & 1.00 & 5.00 & 2.9787 & 1.34309\end{array}$ knowing figures of speech.

12. I prefer learning inversions' models in texts $\begin{array}{lllll}47 & 1.00 & 5.00 & 2.8511 & 1.12247\end{array}$

The 12-item questionnaire was sent online to the participants. Only 47 responded. It was designed to reveal the learners' perception about incorporating stylistics models of inversion in teaching grammar. Table 4 shows that the students in general preferred incorporating stylistic models of inversion in grammar courses because stylistic models equip them with systematic modality on how to understand and analyse literary texts that contain stylistic models of inversion. They also felt that stylistic models of inversion motivate their mental faculty to autonomous creativity in writing and in interpreting text they read. More importantly, students came up with the idea that literary writers intentionally and systematically use the models of inversion in literature for aesthetic purposes. Finally, learners show no differences between using sentences or texts in learning inversion. Both modalities are the same since the structures of inversion models are clear to them.

\section{Discussion}

The study involved students who took four sections of grammar courses. The result shows that there is a positive impact of incorporating stylistic models of inversion in teaching grammar on students' comprehension of literary texts. The majority of the participants answered the test items correctly. They identify the sentences that contain stylistic models of inversion and revert them to normal grammatical order. This conclusion aligns with Giovanelli and Clayton (2016) who stress on the importance of considering different stylistic principles in teaching language. It is these stylistic devices that make literary texts foregrounding. They also improve students' academic performance specifically in creative writing and in interpreting

The Impact of Incorporating Stylistic Models of Inversion in Teaching Grammar on Students' Comprehension of Literary Text 
texts. This study is consistent with what Nørgaard et al. (2010) and Widdowson (1975) say about pedagogical stylistics. They affirm that pedagogical stylistics increases the learners' perception of different features of language and the ways in which they function in various types of text with miscellaneous effects. It is also in line with the Department of English (DfE, 2013) which suggests that it is mandatory to include stylistic implications in teaching grammar because it makes students able to elicit how the different linguistic devices such as figures of speech, vocabulary choice, grammar, and text structure, assist in understanding meaning. Myhill et al. (2012) in their study made use of rhetorical grammar and principles from stylistics and they concluded that using contextualised grammar in teaching could have positive results on students' writing ability and metalinguistic.

The study has a positive impact on learners. The post-test results, as seen above, show satisfying performance of learners in understanding and analysing stylistic models of inversion in texts. Moreover, it adds a new cognitive dimension represented in their readiness to write simple literary texts that contain inversion. These results align with Cushing (2018) who stresses on the importance of enhancing autonomous texts analysis. Learners in the questionnaire reported that after they have been taught the stylistic models of inversion, they were able to infer inversion form any literary texts and were capable to analyse and understand them. The strategy they have learned, during tutorials, helps them to discover inversion models and to revert them to normal words to ease understanding. They also stress on the importance of incorporating stylistic models of inversion in grammar courses.

\section{Conclusion}

The study investigates the impact of incorporating stylistic models of inversion in teaching grammar on comprehending literary texts. Stylistic inversion is a syntactic device that occurs a lot in literary texts. The findings of the study stresses on the importance of incorporating stylistic models of inversion in grammar courses because it helps learners to understand literary texts and revert the inverted sentences into normal word order (uninverted). As shown from the test, the textbased group and sentence-based group in Grammar III scored high performance with $(M=1.50)$ and with $(M=1.40)$ respectively. Similarly, in Grammar IV, the textbased group scored $(M=1.61)$ and sentence-based group scored $(M=1.44)$. This results shows that incorporating stylistic models of inversion in grammar courses facilitates comprehending literary texts. As part of pedagogical stylistics, the foreign language teachers may benefit from other stylistic devices at the syntactic level to include them in teaching grammar to have a perfect link between stylistic implications and teaching grammar. The significance of considering all stylistic devices at syntactic level in learning grammar facilitates understanding and analysing literary texts in general. The study has two limitations; firstly, female students were are not included in this study due to university policy regarding coeducation. Female teachers only teach female students and vice versa. Secondly the grammar courses teachers' opinions about incorporating inversion models in grammar courses were not included in this study due to research boundaries. The study suggests further studies on implying different stylistic principles at syntactic

The Impact of Incorporating Stylistic Models of Inversion in Teaching Grammar on Students' Comprehension of Literary Text 
level in teaching grammar because of their importance in boosting literary and nonliterary text comprehension.

\section{Acknowledgement}

The researcher is sincerely thankful for the students at King Khalid University who participated in this study.

\section{References}

Anees, I. (2016). Sir Aloghah. Egypt: Egyptian Anglo library.

Bakhtin, M. M. (2004). Dialogic origin and dialogic pedagogy of grammar: Stylistics in teaching Russian language in secondary school. Journal of Russian \& East European Psychology, 42(6), 12-49.

Bailyn, J. F. (2004). Generalised inversion. Natural Language \& Linguistics Theory, 22(1), 1-50.

Baldick, C. (1996). The concise Oxford dictionary of literary terms. Oxford: Oxford University Press.

Borg, S., \& Burns, A. (2008). Integrating grammar in adult TESOL classrooms. Applied Linguistics, 29(3), 456-482.

Burke, M., Csabi, S., Week, L., \& Zerkowitz, J. (Eds.). (2012). Pedagogical stylistics: Current trends in language, literature and ELT. Bloomsbury Publishing.

Cancellaro, K. (2015). Investigating the gap between L2 grammar textbooks and authentic speech: Corpus-based comparisons of reported speech. Journal of Language and Education, 1(1), 6-11. Retrieved from https://doi.org/10.17323/2411-7390-2015-1-1-6-11

Carter, R., \& Nash, W. (1990). Seeing through language. Oxford: Blackwell.

Clark, U., \& Zyngier, S. (2003). Towards a pedagogical stylistics. Language and Literature, 12(4), 339-351.

Crystal, D. (1997). The Cambridge Encyclopedia of Language. Cambridge: Cambridge University Press.

Crystal, D. (2011). A dictionary of linguistics and phonetics. Chichester, UK: John Wiley \& Sons.

Cushing, I. (2018). Stylistics goes to school. Language and Literature, 27(4), 271-285.

Cushing, I. (2018). 'Suddenly, I am part of the poem': Texts as worlds, readerresponse and grammar in teaching poetry. English in Education, 52(1), 7-19.

Culicover, P. W., \& Levine, R. D. (2001). A reconsideration of locative inversion. Natural Language and Linguistic Theory, 19, 283-310.

Department for English. (2013). English literature GCSE subject content and assessment objectives. Retrieved from https://assets.publishing.service.gov.uk/governemnt/upload/system/upload /attachement_data/file/254497/GCSE_English_language.pdf

Dryer, M. S. (2005). 81 Order of subject, object, and verb. In M. S. Dryer, \& M. Haspelmath. (Eds.), The world atlas of language structures online (pp. 330333). Oxford: Oxford University Press.

The Impact of Incorporating Stylistic Models of Inversion in Teaching Grammar on Students' Comprehension of Literary Text 
Fogal, G. G. (2015). Pedagogical stylistics in multiple foreign language and second language contexts: A synthesis of empirical research. Language and Literature, 24(1), 54-72.

Ghanizadeh, A., \& Jahedizadeh, S. (2016). EFL teachers' teaching style, creativity, and burnout: A path analysis approach. Cogent Education, 3(1). Retrieved from https://doi.org/10.1186/s40862-016-0021-8

Giovanelli, M., \& Clayton, D. (Eds.). (2016). Knowing about language: Linguistics and the secondary English classroom. Abingdon, UK: Routledge.

Giovanelli, M. (2010). Pedagogical stylistics: A text world theory approach to the teaching of poetry. English in Education, 44(3), 214-231.

Galperin, I. R. (1977). Stylistic.: Moscow: Higher School.

Hall, G. (2014). Pedagogical stylistics. In M. Burke. (Ed.), The Routledge handbook of stylistics (pp. 239-252). London: Routledge.

Huang, Y. (2019). The application of stylistic analysis in college English teaching. Retrieved from https://doi.org/10.2991/icem-18.2019.145

Jesperson, O. (1943). Essentials of English grammar. London: Allen and Unwin.

Jeffries, L., \& McIntyre, D. (2010). Stylistics. Cambridge University Press.

Kang, C. (2018). Stylistics and the teaching of advanced English for senior English majors. Theory Practice in Language Studies, 8(10), 1346-1350.

Myhill, D. A., Jones, S. M., Lines, H., \& Watson, A. (2012). Re-thinking grammar: The impact of embedded grammar teaching on students' writing and students' metalinguistic understanding. Research Papers in Education, 27(2), 139-166.

Nespor, J. (1987). The role of beliefs in the practice of teaching. Journal of Curriculum Studies, 19(4), 317-328.

Nørgaard, N., Montoro, R., \& Busse, B. (2010). Key terms in stylistics. New York, NY: Continuum International Pub. Group.

Short, M. (1996). Exploring the language of poems, plays and prose. Essex: Addison Wesley Longman Limited.

Short, M. H. (1984). Speech presentation, the novels and the press. In W. van Peer. (Ed.), The taming of the text (pp. 61-81). London: Routledge.

Simpson, P. (1999). Pedagogical stylistics and literary evaluation. Journal of Literary Studies, 15(34), 510-528.

Simpson, P. (2014). Just what is narrative urgency? Language and Literature, 23(1), 3-22.

Song, J. J. (2012). Word order. Cambridge: Cambridge University Press.

Sotirova, V. (2016). Empirical stylistics as a learning and research tool in the study of narrative viewpoint. Scientific approaches to literature in learning environments, 227-252.

Watson, A. (2015). The problem of grammar teaching: A case study of the relationship between a teacher's beliefs and pedagogical practice. Language and Education, 29(4), 332-346.

Whiteley, S., \& Canning, P. (2017). Reader response research in stylistics. Language and Literature, 26(2), 71-87.

Widdowson, H. G. (1975). Stylistics and the teaching of literature. London: Routledge.

The Impact of Incorporating Stylistic Models of Inversion in Teaching Grammar on Students' Comprehension of Literary Text 